\title{
Analysis of the Thermal Stability of PTFE Nanoparticles Enriched Coating on Material Made from Al-Si Alloy
}

Igor Zuravsky, Jaroslava Svobodova, Irena Lysonkova, Michal Lattner, Josef Ponikelsky

Faculty of Mechanical Engineering, J. E. Purkyne University in Usti nad Labem. Pasteurova 3334/7, 40001 Usti nad Labem. Czech Republic. E-mail: i.zuravsky@seznam.cz

The article focuses on technological procedures of coating of metal molds made from Al-Si alloys, especially used for making tyres. The idea is to create coating on aluminium based metal molds in order to reach a higher number of production cycles between individual cleaning operations in tyre making technology. The experiment was based on a preparation of experimental samples, which were coated with a teflon based product with the addition of nanoparticles $\left(\mathrm{eg}\right.$. $\left.\mathrm{TiO}_{2}\right)$, in other words, particles as large as tens of nanometres, which were mixed into the teflon solution in a particular concentration. After creating the coating, the experimental samples were put under a thermal load in various thermal modes. Futhermore, roughness, coating resistance, and changes after the thermal load were subjects of the study.

Keywords: Thermal stability, PTFE coating, nanoparticles, nanocoating, nanolayers

\section{Introduction}

There have been more requests on the development of aluminium alloys from the manufacturers of car and aviation industries because of their low density, mechanical properties and corrosion resistance. Nowadays, the main key drivers for the increase of aluminium based manufacturing are car, aviation, and construction industries. This article deals with technological procedures of coating of metal molds made from Al-Si alloys, especially for tyre production. It is about creating coating on the aluminium based metal molds in order to reach a higher number of production cycles between individual cleaning operations in the tyre making technology. Recently, aluminium based materials are used to create metal molds for the tyre production. The metal mold consists of a certain number of segments (8-36) based on the dimensions of the produced tyre. The surface of the metal molds is not modified by any technology of the surface treatment. The selling price of the metal mold depending on the required tyre type can reach hundreds of thousands or even millions of Czech crowns. Each cleaning process causes deterioration of functional areas of the metal mold, which results in reduction of the lifespan. The maintenance of the tyre molds is money and time consuming, and it is given a high priority in order to extend its lifespan. The lifespan is considered to be autonomy of the operational mode of the mold when no maintenance is necessary. These molds are made from an aluminium based alloy of an Al-Si type. One way to extend the operational cycle is to apply protective coating. A very thin layer of the coating is required based on the functionality of the working surface. [1].

The evaluation of the thermal stability of the PTFE nanoparticles enriched coating on a base material made from Al-Si alloy type can be found in the article. The experiment is based on preparation of the experimental samples, which were coated by a teflon based product with the addition of nanoparticles (eg. $\left.\mathrm{TiO}_{2}\right)$, in other words, particles as large as tens of nanometres, which were mixed into the teflon solution in a particular concentration. After creating the coating, the experimental samples were put under a thermal load in various thermal modes. Futhermore, roughness, coating resistance, and changes after the thermal load were subjects of the study.

\section{Preparation and marking of the experi- mental samples}

The same base material was used for all the samples as a part of the research with the only difference being the technology of material coating. Overall, 140 samples were coated. The samples with PTFE $+\mathrm{TiO}_{2}$ are marked with index A. The samples with PTFE coating without the addition of the nanoparticles are marked with index B. Tab. There were 10 samples made for each group to objectively evaluate the results of each of the performed analysis. The samples were subject to thermal loading at different temperatures after the coating was created on all the experimental samples of the A and B type. In total, 7 modes of thermal loading were selected with the order of 1-7. The marking of the experimental samples given the used coatings and thermal loading is shown in Tab. 1. 
Tab. 1 Identification of experimental samples

\begin{tabular}{|c|c|c|c|c|c|c|c|}
\hline & Group 1 & Group 2 & Group 3 & Group 4 & Group 5 & Group 6 & Group 7 \\
\cline { 2 - 8 } & $150{ }^{\circ} \mathrm{C}$ & $200{ }^{\circ} \mathrm{C}$ & $250{ }^{\circ} \mathrm{C}$ & $300{ }^{\circ} \mathrm{C}$ & $350{ }^{\circ} \mathrm{C}$ & $400{ }^{\circ} \mathrm{C}$ & $500{ }^{\circ} \mathrm{C}$ \\
\hline \multirow{2}{*}{ PTFE + TiO2 } & $1 \mathrm{~A}$ & $2 \mathrm{~A}$ & $3 \mathrm{~A}$ & $4 \mathrm{~A}$ & $5 \mathrm{~A}$ & $6 \mathrm{~A}$ & $7 \mathrm{~A}$ \\
& $(1 \div 10)$ & $(1 \div 10)$ & $(1 \div 10)$ & $(1 \div 10)$ & $(1 \div 10)$ & $(1 \div 10)$ & $(1 \div 10)$ \\
\hline \multirow{2}{*}{ PTFE } & $1 \mathrm{~B}$ & $2 \mathrm{~B}$ & $3 \mathrm{~B}$ & $4 \mathrm{~B}$ & $5 \mathrm{~B}$ & $6 \mathrm{~B}$ & $7 \mathrm{~B}$ \\
& $(1 \div 10)$ & $(1 \div 10)$ & $(1 \div 10)$ & $(1 \div 10)$ & $(1 \div 10)$ & $(1 \div 10)$ & $(1 \div 10)$ \\
\hline
\end{tabular}

\subsection{Coating technology of the experimental samples}

One way to extend the working cycle of the molds (eg. for tyre pressing) is to apply protective coating on the surface of the mold. A very thin layer is necessary about the functionality of the working space. PTFE coating is one of the appropriate types of coating as it extends the lifespan in the matter of hundreds of per cent (by $200-400 \%$ as it was already verified by research done at FSI UJEP). There is an effort within this work to further improve the coating by adding particles of titanium dioxide $\left(\mathrm{TiO}_{2}\right)$, in the 'nano' particles scale. Grinding of the powder was done by using a ball-mill Retsch PM 100.

The coating on the surface of the experimental samples was created by the following process:

Chemical products were used during coating of the prepared samples in a form of plates. The specific names and chemical composition of these products are kept confidential with this phase of the research. The individual parameters (temperature, time, $\mathrm{pH}$ of the solution) of the technology are listed in Tab. 2- 4. The $\mathrm{pH}$ values were checked by a $\mathrm{pH}$ meter in the preparation phase of the coating bath.

Tab. 2 Coating parameters and description of P1 - alkaline degreasing

\begin{tabular}{|c|c|c|}
\hline Operational parameters & $\begin{array}{c}\text { Alcaline degreasing (product marking.: } \\
\text { P1) } \\
\text { Two-component degreasing bath }\end{array}$ & Product description \\
\hline Amount of product P1 & $\begin{array}{c}\text { component 1: about } 1.4 \mathrm{~g} / \mathrm{l} \text {; component } \\
2: \text { about } 1.0 \mathrm{~g} / 1\end{array}$ & $\begin{array}{c}\text { Alcaline degreasing containing two- } \\
\text { component pickling and degreasing } \\
\text { agent for aluminium and its alloys }\end{array}$ \\
\hline Temperature & $55^{\circ} \mathrm{C}$ & 5 min. \\
\hline Degreasing & submersion & \\
\hline Duration of adjustment & &
\end{tabular}

Tab. 3 Coating parameters and description of P2 - zirkonium nanopassivation

\begin{tabular}{|c|c|c|}
\hline Operational parameters & $\begin{array}{l}\text { Zirconium nanopassivation (product } \\
\text { marking.: P2) }\end{array}$ & Product description \\
\hline Amount of product P2 & $20-40 \mathrm{~g} / 1 \mathrm{P} 2$ in demineralised water & \multirow{7}{*}{$\begin{array}{l}\text { A Liquid product based on } \\
\text { hexafluoro-zirconic acid that is used for } \\
\text { creating nanomolecular surfaces Sol - } \\
\text { gel of technologies for steel and alumin- } \\
\text { ium surfaces protection }\end{array}$} \\
\hline $\begin{array}{l}\text { Temperature of appli- } \\
\text { cation }\end{array}$ & Room temperature & \\
\hline Duration of adjustment & $2 \min$ & \\
\hline Application & submersion & \\
\hline $\mathrm{pH}$ value & 5.2 & \\
\hline Drying conditions & $150^{\circ} \mathrm{C}$ & \\
\hline Time & $15 \mathrm{~min}$ & \\
\hline
\end{tabular}

Tab. 4 Coating parameters and description of P3 - PTFE

\begin{tabular}{|c|c|c|}
\hline Operational parameters & PTFE coating (product marking.: P3) & Product description \\
\hline Amount of product P3 & $8-10 \mathrm{~g} / 1 \mathrm{P} 3$ in demineralised water & \\
\cline { 1 - 2 } $\begin{array}{c}\text { Temperature of appli- } \\
\text { cation }\end{array}$ & $60{ }^{\circ} \mathrm{C}$ & $\begin{array}{c}\text { A Liquid straight component product } \\
\text { based on PTFE to treat aluminium sur- } \\
\text { face }\end{array}$ \\
\hline Duration of adjustment & $10-15 \mathrm{~min}$ & \\
\hline Application & submersion & \\
\hline pH value & $7.8-8.5$ & \\
\hline Drying conditions & $150{ }^{\circ} \mathrm{C}$ & \\
\hline
\end{tabular}


The degreasing bath consisted of a two-component product marked as $\mathrm{P} 1$, which was stirred in demineralised water in a prescribed amount. The concentrations of chemicals of the particular product were always used with the recommendation of the manufacturer of these products. The passivation bath consists of $\mathrm{P} 2$ product and demineralised water. The $\mathrm{pH}$ factor can be in case of a passivation bath regulated by adding the established product. This step of nanopassivation of the surface of the experimental samples serves as a surface treatment of the base material after degreasing, and at the same time after preparation of the surface before application of the final PTFE coating. The final coating is created on the surface of the base material by using a product marked as $\mathrm{P} 3$ and demineralised water, in which it is applied in a prescribed amount.

A formation scheme of the PTFE coating on the surface of the experimental samples with the description of specific technological parameters of the coating can be seen in Fig. 1.



Fig. 1PTFE coating formation scheme

In the second phase of the coating $\mathrm{TiO}_{2}$ nanoparticles were added into $\mathrm{P} 3$ in a percentage ratio of 0,01 $\%$ against the overal capacity of the coating bath. In the previous research which was done at FSI UJEP, it was found out that $0,01 \%$ ratio appears to be the best concentration of $\mathrm{TiO}_{2}$ in the PTFE solution. Other concentrations were tested as well, however, this was the best ratio with consideration to the final coating and anchoraging of $\mathrm{TiO}_{2}$ in this coating. That is why this $\mathrm{TiO}_{2}$ concentration was used for the purpose of the experiment in my diploma thesis. [2].

The Coating formation scheme of PTFE $+\mathrm{TiO}_{2}$ on the surface of the experimental samples with a description of technological parameters is mentioned in Fig. 2.

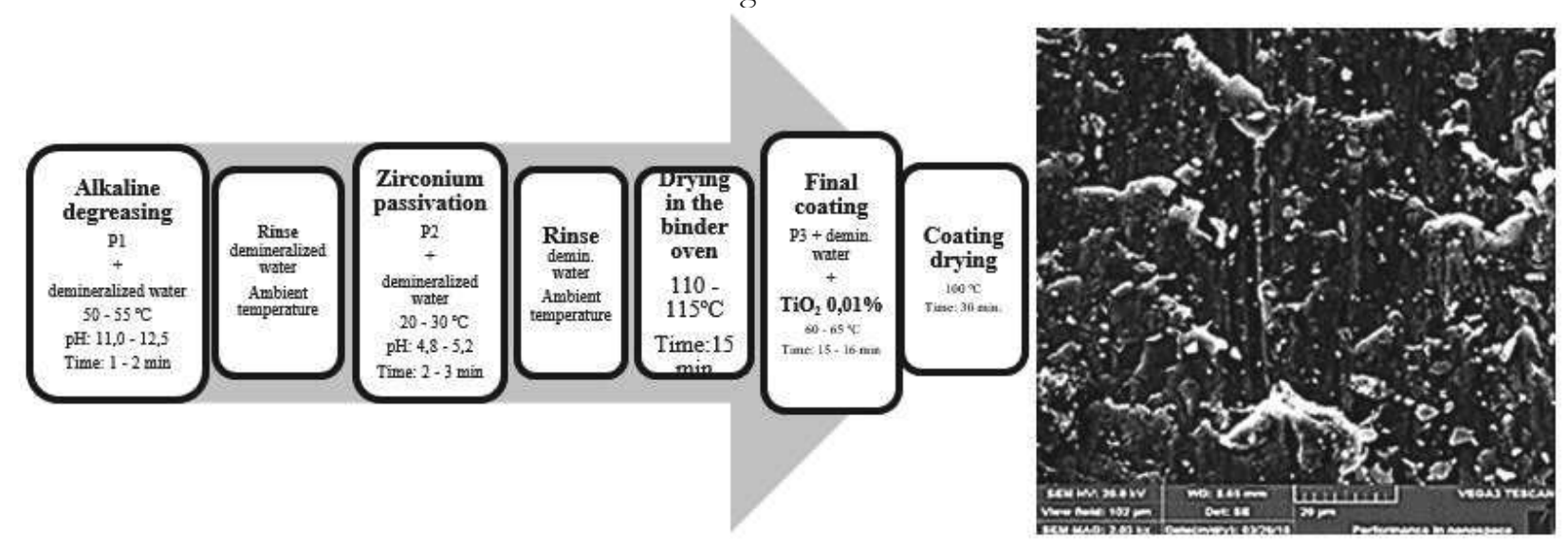

Fig. 2 Coating formation scheme PTFE $+\mathrm{TiO}_{2}$

\subsection{Thermal loading}

140 samples with the coating (PTFE, PTFE + $\mathrm{TiO}_{2}$ ) were used for the thermal loading. The purpose of this work is to study the thermal stability and identification of potential changes on the surface of the experimental samples post coating. In total, there were seven groups created based on the temperature of the load. Each of these groups was put under the load for 30 and 60 minutes. Tab. 5 shows the marking of all the experimental samples which were used for the testing of the thermal stability according to set conditions and parameters [3].

The temperature of the loading was chosen with respect to the operating temperature of the mold for 
tyre pressing. Considering the purpose of improving the properties of the PTFE coating by adding nanoparticles, I wanted to find out with this experiment, whether there is degradation of the coating with respect to temperature or time. The temperature of 500 ${ }^{\circ} \mathrm{C}$ is selected as the maximum since the base material itself could be affected by exceeding it.

Tab. 5 Thermal loading according to specified conditions

\begin{tabular}{|c|c|c|c|c|c|c|c|c|}
\hline \multirow{2}{*}{ Coating } & \multirow{2}{*}{ Duration of loading } & Gr. 1 & Gr. 2 & Gr. 3 & Gr. 4 & Gr. 5 & Gr. 6 & Gr. 7 \\
\hline & & $150{ }^{\circ} \mathrm{C}$ & $200^{\circ} \mathrm{C}$ & $250{ }^{\circ} \mathrm{C}$ & $300^{\circ} \mathrm{C}$ & $350{ }^{\circ} \mathrm{C}$ & $400^{\circ} \mathrm{C}$ & $500^{\circ} \mathrm{C}$ \\
\hline \multirow{10}{*}{$\begin{array}{c}\text { PTFE + } \\
\mathrm{TiO}_{2}\end{array}$} & \multirow{5}{*}{$30 \mathrm{~min}$} & 1A1 & 2A1 & 3A1 & 4A1 & 5A1 & 6A1 & 7A1 \\
\hline & & 1A2 & 2A2 & $3 \mathrm{~A} 2$ & $4 \mathrm{~A} 2$ & $5 \mathrm{~A} 2$ & $6 \mathrm{~A} 2$ & 7A2 \\
\hline & & 1A5 & 2A5 & 3 A5 & 4A5 & 5 A 5 & 6A5 & 7A5 \\
\hline & & $1 \mathrm{~A} 6$ & $2 \mathrm{~A} 6$ & $3 \mathrm{~A} 6$ & $4 \mathrm{~A} 6$ & $5 \mathrm{~A} 6$ & 6A6 & 7A6 \\
\hline & & 1A7 & $2 \mathrm{~A} 7$ & $3 \mathrm{~A} 7$ & 4A7 & 5A7 & 6A7 & 7A7 \\
\hline & \multirow{5}{*}{$60 \mathrm{~min}$} & 1A3 & $2 \mathrm{~A} 3$ & $3 \mathrm{~A} 3$ & $4 \mathrm{~A} 3$ & $5 \mathrm{~A} 3$ & 6A3 & $7 \mathrm{~A} 3$ \\
\hline & & 1A4 & 2A4 & 3A4 & 4A4 & 5A4 & 6A4 & 7A4 \\
\hline & & 1A8 & $2 \mathrm{~A} 8$ & $3 \mathrm{~A} 8$ & $4 \mathrm{~A} 8$ & $5 \mathrm{~A} 8$ & 6A8 & 7A8 \\
\hline & & 1A9 & 2A9 & 3A9 & 4A9 & $5 \mathrm{~A} 9$ & 6A9 & 7A9 \\
\hline & & 1A10 & 2A10 & 3A10 & 4A10 & $5 \mathrm{~A} 10$ & 6A10 & 7A10 \\
\hline \multirow{10}{*}{ PTFE } & \multirow{5}{*}{$30 \mathrm{~min}$} & 1B1 & 2B1 & 3B1 & 4B1 & 5B1 & 6B1 & 7B1 \\
\hline & & 1B2 & 2B2 & 3B2 & 4B2 & $5 \mathrm{~B} 2$ & 6B2 & 7B2 \\
\hline & & 1B5 & 2B5 & $3 \mathrm{~B} 5$ & 4B5 & $5 \mathrm{~B} 5$ & 6B5 & 7B5 \\
\hline & & $1 \mathrm{~B} 6$ & $2 \mathrm{~B} 6$ & $3 \mathrm{~B} 6$ & $4 \mathrm{~B} 6$ & $5 \mathrm{~B} 6$ & 6B6 & 7B6 \\
\hline & & $1 \mathrm{~B} 7$ & $2 \mathrm{~B} 7$ & $3 \mathrm{~B} 7$ & 4B7 & $5 \mathrm{~B} 7$ & $6 \mathrm{~B} 7$ & 7B7 \\
\hline & \multirow{5}{*}{$60 \mathrm{~min}$} & 1B3 & 2B3 & $3 \mathrm{~B} 3$ & 4B3 & $5 \mathrm{~B} 3$ & 6B3 & $7 \mathrm{~B} 3$ \\
\hline & & 1B4 & 2B4 & 3B4 & 4B4 & $5 \mathrm{~B} 4$ & 6B4 & 7B4 \\
\hline & & 1B8 & 2B8 & $3 \mathrm{~B} 8$ & 4B8 & $5 \mathrm{~B} 8$ & 6B8 & 7B8 \\
\hline & & 1B9 & 2B9 & 3B9 & 4B9 & $5 B 9$ & 6B9 & 7B9 \\
\hline & & 1B10 & 2B10 & 3B10 & 4B10 & $5 \mathrm{~B} 10$ & 6B10 & 7B10 \\
\hline
\end{tabular}

\subsection{Measuring of the surface roughness}

By measuring the surface roughness the aim was to find out whether thermal loading affects the roughness of the surface of the experimental samples. The measurement was done before and after the loading, so that the results could be compared and evaluated afterwards. The roughness measurement was carried out on a Hommel Tester T8000 apparatus. The measurement on this apparatus is standardised according to the ČSN EN ISO 4287 norm. The measurement was carried out on the base material before and after coating (marked as sample 1-3), in a way that it would be possible to compare the influence of the coating on the surface roughness. Moreover, the roughness measurement of the thermally loaded and unloaded experimental samples was performed. Thermal loading of the samples was done with respect to the set temperatures as listed in Tab. 5 in the previous section. For the measurement, two samples were selected from each group $(1 \mathrm{~A}, 2 \mathrm{~A}, 2 \mathrm{~B}, \ldots)$. Only the measurement of the surface roughness of the base material was carried out on three samples. Each of these samples was measured ten times.

The following parameters of roughness were chosen for the evaluation of the measurement- $\mathrm{R} a$ (average arithmetic deviation of the assessed surface), Rz (greatest height of the profile) and Rt (overal height of the profile) [5].

When comparing the values of surface roughness of the base material with the values of the roughness of the already coated material, it is apparent that the values of the coated material (without thermal loading) differ. As can be seen in Fig. 3 and 4, the roughness values of the coated material $\left(R a, R_{z}\right.$ i $\left.R t\right)$ are lower than the base material. The coating helped to level out the inequalities of the surface of the studied material. The recorded values were processed in Excel. The arithmetic average was calculated from the roughness values to provide greater clarity of the results. The tables placed under the bar charts show the average values of the surface roughness of the individual experimental samples and the roughness parameters.

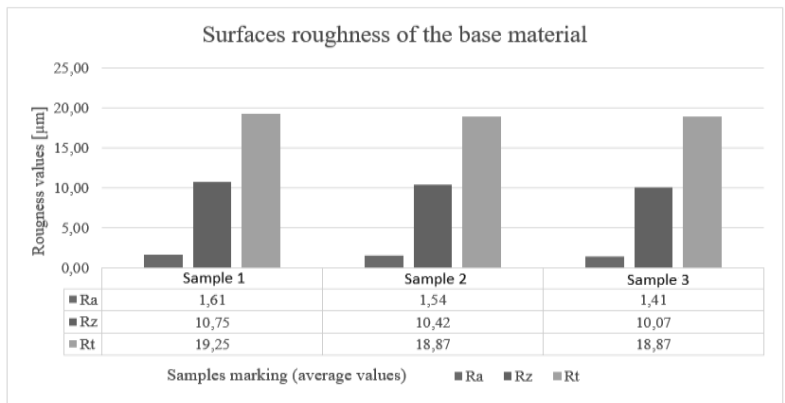

Fig. 3 Surface roughness of uncoated base material 


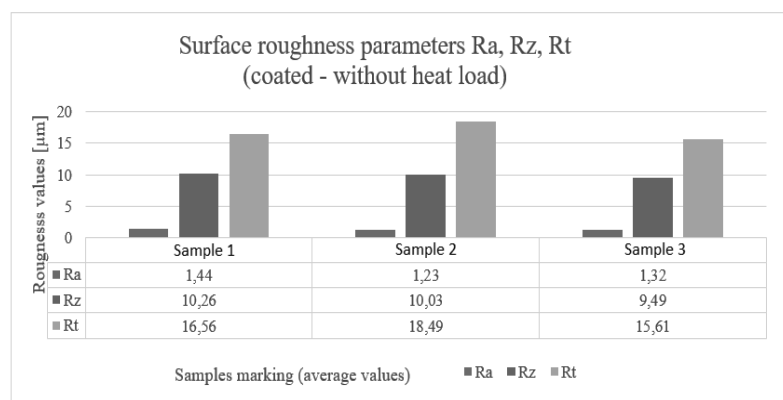

Fig. 4 Surface roughness of coated base materiál (without thermal loading)

The samples with the PTFE coating were put under load for 30 and 60 minutes. The experimental samples which were under load for 30 minutes displayed lower roughness values, which is apparent in Fig. 5 and 6. The lowest values of roughness with the PTFE coating was displayed by the $2 \mathrm{~B}$ sample group, which was put under load for 30 minutes. The group $2 \mathrm{~B}$ represents the PTFE coating which was exposed to the temperature of $200^{\circ} \mathrm{C}$. Conversely, as can be seen in Fig. 7 and 8 , the highest values of roughness were shown in the $3 \mathrm{~B}$ sample group which was put under load for 60 minutes. The 3B group represents the PTFE coating which was exposed to the temperature of $250^{\circ} \mathrm{C}$.

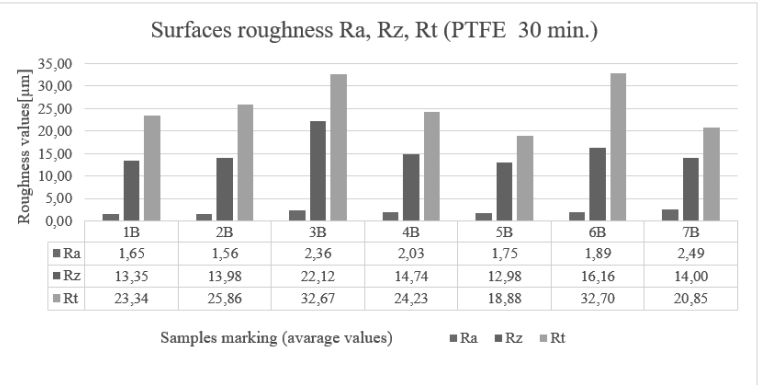

Fig. 5 Surface roughness for PTFE coating (thermal load for 30 min.)

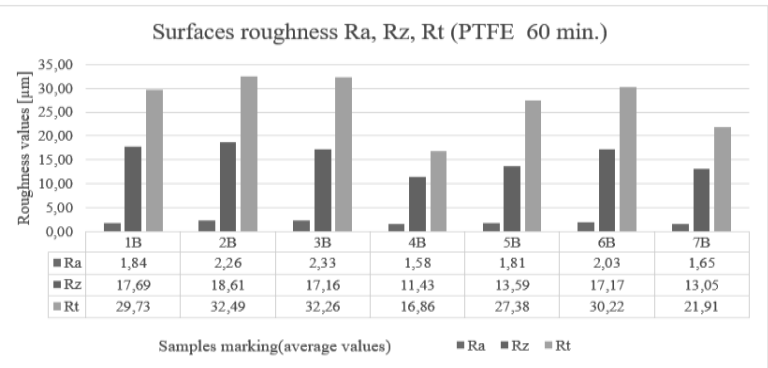

Fig. 6 Surface roughness for PTFE coating (thermal load for 60 min.)

The PTFE coating samples with the addition of $\mathrm{TiO}_{2}$ nanoparticles were also put under load for 30 and 60 minutes. The 7B sample group showed the lowest roughness values of PTFE $+\mathrm{TiO}_{2}$ coating, and it was under load for 60 minutes. The group $7 \mathrm{~B}$ represents the PTFE $+\mathrm{TiO}_{2}$ coating which was exposed to the temperature of

$500{ }^{\circ} \mathrm{C}$. Conversely, as can be seen in Fig. 7 and 8, the highest values of roughness were shown in the 4B sample group which was put under load for 60 minutes. The group 4B represents the PTFE $+\mathrm{TiO}_{2}$ coating which was exposed to the temperature of 300 ${ }^{\circ} \mathrm{C}$.

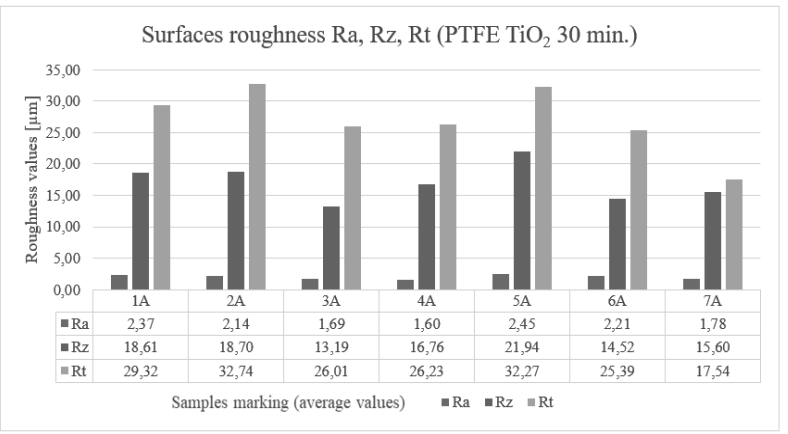

Fig. 7 Surface roughness for PTFE $+\mathrm{TiO}_{2}$ coating (thermal load for $30 \mathrm{~min}$.)

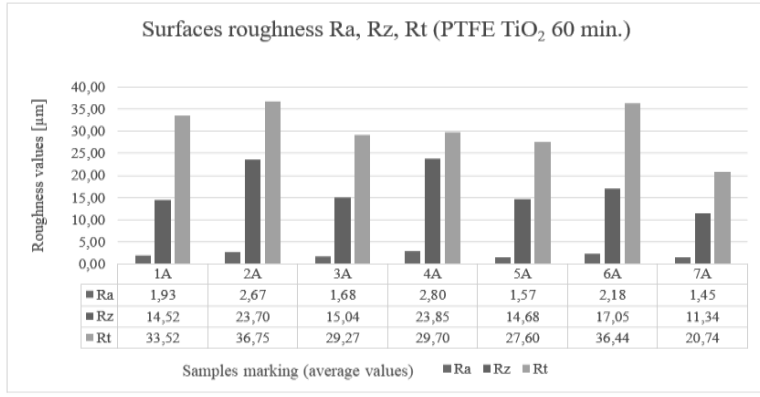

Fig. 8 Surface roughness for PTFE $+\mathrm{TiO}_{2}$ coating (thermal load for $60 \mathrm{~min}$.)

\subsection{Measurement of the coefficient of friction - Tribo-} meter

Deterioration and friction are sensitive to a change in conditions (change in temperature, load or moisture). Tribometers are machines used for this case [4]. The measurement of the coefficient of friction was carried out on a Bruker UMT TriboLab apparatus. It is a multifunctional tribometer, which represents a flexible modular system used for all common tribological tests. A ball with a diameter of $12.7 \mathrm{~mm}$ was used for the tribometer measurements, and it is provided straight from the manufacturer. During the measurement, the ball was being turned slightly to avoid affecting the measurement caused by the applied coating. The ball moved on a $10 \mathrm{~mm}$ track with $4 \mathrm{~N}$ or $2 \mathrm{~N}$ load. The coefficient of friction measurement was always performed on one sample of each group at a time, and each of these samples was measured five times. The average values of the coefficient of friction are listed in Tab 6, 7, 8. [6]. 
Tab. 6 Average values of coefficient of friction material and material without thermal loading

\begin{tabular}{|c|c|c|c|c|c|}
\hline Sample name & Coating & $\begin{array}{c}\text { Load duration } \\
{[\mathrm{min}]}\end{array}$ & $\begin{array}{c}\text { Temperature } \\
{\left[{ }^{\circ} \mathrm{C}\right]}\end{array}$ & $\begin{array}{c}\text { Average value of } \\
\text { CoF }\end{array}$ & $\begin{array}{c}\text { Conditions of } \\
\text { measurement }\end{array}$ \\
\hline Base material & 0 & 0 & 0 & 0.148 & 1 \\
\hline 6A10 & PTFE $+\mathrm{TiO}_{2}$ & 0 & 0 & 0.101 & 1 \\
\hline 6B10 & PTFE & 0 & 0 & 0.100 & 1 \\
\hline
\end{tabular}

In Tab. 6, it can be seen that the base material reaches the highest average values of coefficient of friction without being coated and thermally loaded. Conversely, the sample 6B10 shows the lowest average values. It is the sample with the PTFE coating which was not put under thermal loading. There is an increase of the coefficient of friction with the applied coating (PTFE or PTFE $+\mathrm{TiO}_{2}$ ).

Tab. 7 Average friction coefficient values for PTFE coated samples

\begin{tabular}{|c|c|c|c|c|c|}
\hline Sample name & Coating & $\begin{array}{c}\text { Load duration } \\
{[\mathrm{min}]}\end{array}$ & $\begin{array}{c}\text { Temperature } \\
{\left[{ }^{\circ} \mathrm{C}\right]}\end{array}$ & $\begin{array}{c}\text { Average value of } \\
\text { CoF }\end{array}$ & $\begin{array}{c}\text { Conditions of } \\
\text { measurement }\end{array}$ \\
\hline 1B5 & PTFE & 30 & 150 & 0.163 & 1 \\
\hline 1B9 & PTFE & 60 & 150 & 0.102 & 1 \\
\hline 2B7 & PTFE & 30 & 200 & 0.103 & 1 \\
\hline 2B10 & PTFE & 60 & 200 & 0.119 & 1 \\
\hline 3B7 & PTFE & 30 & 250 & 0.182 & 2 \\
\hline 3B10 & PTFE & 60 & 250 & 0.184 & 2 \\
\hline 4B6 & PTFE & 30 & 300 & 0.165 & 2 \\
\hline 4B8 & PTFE & 60 & 300 & 0.435 & 2 \\
\hline 5B6 & PTFE & 30 & 350 & 0.861 & 2 \\
\hline 5B9 & PTFE & 60 & 350 & 0.838 & 2 \\
\hline 6B6 & PTFE & 30 & 400 & 0.846 & 1.335 \\
\hline 6B8 & PTFE & 60 & 400 & 1.197 & 1.118 \\
\hline 7B6 & PTFE & 30 & 500 & & \\
\hline 7B9 & PTFE & 60 & 500 & & \\
\hline
\end{tabular}

The PTFE coating degraded at a temperature of $350{ }^{\circ} \mathrm{C}$, which is reflected in a sharp increase of the friction coefficient for this temperature. The sample 1B9 shows the lowest average value of the friction coefficient. It is the sample with the PTFE coating which was put under load at $150{ }^{\circ} \mathrm{C}$ for 60 minutes. Conversely, the sample $6 \mathrm{~B} 8$ shows the highest values of coefficient of friction. It is the sample with the PTFE coating which was put under load at $400{ }^{\circ} \mathrm{C}$ for $60 \mathrm{mi}-$ nutes.

Tab. 8 Average friction coefficient values for PTFE coated samples PTFE + TiO2

\begin{tabular}{|c|c|c|c|c|c|}
\hline Sample name & Coating & $\begin{array}{l}\text { Load duration } \\
\text { [min] }\end{array}$ & $\begin{array}{c}\text { Temperature } \\
{\left[{ }^{\circ} \mathrm{C}\right]}\end{array}$ & $\begin{array}{c}\text { Average value of } \\
\mathrm{CoF}\end{array}$ & $\begin{array}{l}\text { Conditions of } \\
\text { measurement }\end{array}$ \\
\hline $1 \mathrm{~A} 5$ & $\mathrm{PTFE}+\mathrm{TiO}_{2}$ & 30 & 150 & 0.165 & 1 \\
\hline 1A10 & $\mathrm{PTFE}+\mathrm{TiO}_{2}$ & 60 & 150 & 0.115 & 1 \\
\hline $2 \mathrm{~A} 7$ & $\mathrm{PTFE}+\mathrm{TiO}_{2}$ & 30 & 200 & 0.113 & 1 \\
\hline $2 \mathrm{~A} 8$ & $\mathrm{PTFE}+\mathrm{TiO}_{2}$ & 60 & 200 & 0.201 & 1 \\
\hline $3 \mathrm{~A} 6$ & $\mathrm{PTFE}+\mathrm{TiO}_{2}$ & 30 & 250 & 0.106 & 1 \\
\hline $3 \mathrm{~A} 8$ & $\mathrm{PTFE}+\mathrm{TiO}_{2}$ & 60 & 250 & 0.179 & 1 \\
\hline $4 \mathrm{~A} 8$ & $\mathrm{PTFE}+\mathrm{TiO}_{2}$ & 60 & 300 & 1.297 & 2 \\
\hline $4 \mathrm{~A} 6$ & $\mathrm{PTFE}+\mathrm{TiO}_{2}$ & 30 & 300 & 1.134 & 2 \\
\hline $5 \mathrm{~A} 7$ & $\mathrm{PTFE}+\mathrm{TiO}_{2}$ & 30 & 350 & 1.182 & 2 \\
\hline $5 \mathrm{~A} 8$ & $\mathrm{PTFE}+\mathrm{TiO}_{2}$ & 60 & 350 & 0.879 & 2 \\
\hline $6 \mathrm{~A} 5$ & $\mathrm{PTFE}+\mathrm{TiO}_{2}$ & 30 & 400 & 1.110 & 2 \\
\hline $6 \mathrm{~A} 9$ & $\mathrm{PTFE}+\mathrm{TiO}_{2}$ & 60 & 400 & 1.134 & 2 \\
\hline $7 \mathrm{~A} 8$ & $\mathrm{PTFE}+\mathrm{TiO}_{2}$ & 60 & 500 & 1.182 & 2 \\
\hline $7 \mathrm{~A} 6$ & $\mathrm{PTFE}+\mathrm{TiO}_{2}$ & 30 & 500 & 0.879 & 2 \\
\hline
\end{tabular}


There was a significant increase of the coefficient at the temperature of $300^{\circ} \mathrm{C}$. The sample $3 A 6$ shows the lowest friction coefficient. It is the sample with the PTFE $+\mathrm{TiO}_{2}$ coating which was put under load at 150 ${ }^{\circ} \mathrm{C}$ for 30 minutes. Conversely, the sample $4 A 8$ shows the highest values of coefficient of friction. This sample was put under load at $300{ }^{\circ} \mathrm{C}$ for $60 \mathrm{~min}$.

\subsection{SEM and EDS analysis}

The presence of the PTFE coating on the surface of the sample and its uniformity were proven by using the SEM and ESD analysis. The experimental samples were evaluated by using a TESCAN VEGA 3 electron microscope, which is available in the laboratories at UTM FSI UJEP. The thickness of the surface layer is measured based on the images of the surface layer taken by the electron microscope (fig. 9). The thickness ranges between 10 and $20 \mu \mathrm{m}$ and it is a homogeneous layer, but uneven.

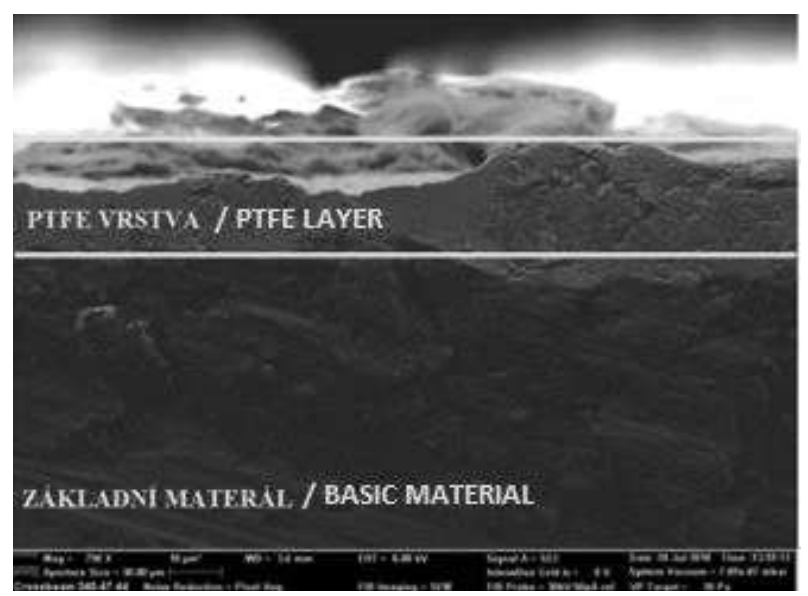

Fig. 9 Coating thickness PTFE

SEM proves expulsion of the PTFE coating on the surface (fig. 10 and 11). The coating covers the whole surface of the sample, but it is not compact. It is expelled in a form of scale fragments. The EDS analysis complements the SEM (fig. 12, Tab. 9) and with those elements typical for PTFE were identified, namely C and $\mathrm{F}$. Zirconium nanopassivation is a substrate under the PTFE coating and that is why $\mathrm{Zr}$ is also present. The other elements are closely linked with the base material (Al, $\mathrm{Si}, \mathrm{Mg})$.

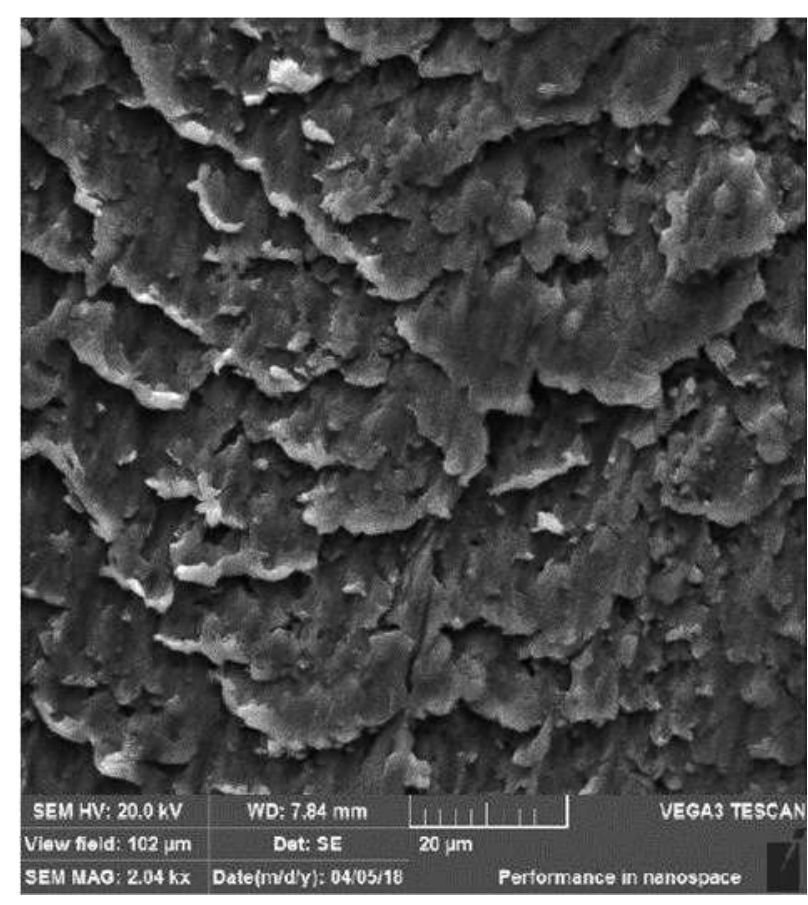

Fig. 10 Sample surface with PTFE coating

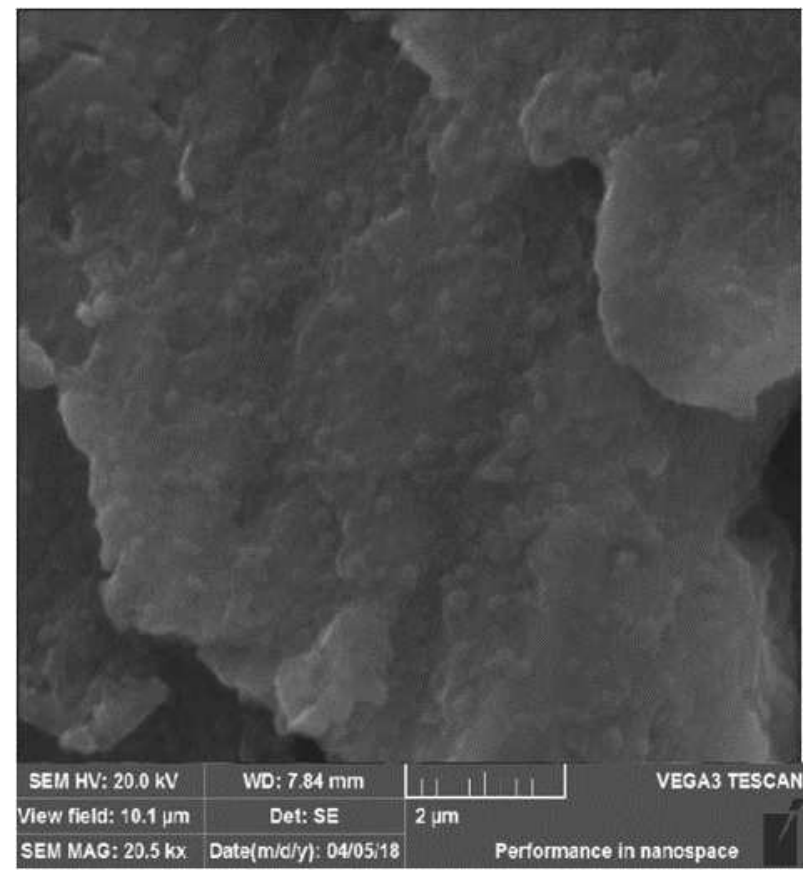

Fig. 11 PTFE coating on the sample surface

Tab. 9 EDS result of analysis of the PTFE coating

\begin{tabular}{|c|c|c|}
\hline Element & Norm. C [\%] & Norm. C [\%] \\
\hline $\mathrm{Al}$ & 70.16 & 58.29 \\
\hline $\mathrm{O}$ & 6.19 & 8.67 \\
\hline $\mathrm{C}$ & 11.90 & 22.21 \\
\hline $\mathrm{F}$ & 4.04 & 4.76 \\
\hline $\mathrm{Si}$ & 6.44 & 5.14 \\
\hline $\mathrm{Zr}$ & 0.36 & 0.09 \\
\hline $\mathrm{Mg}$ & 0.91 & 0.84 \\
\hline
\end{tabular}



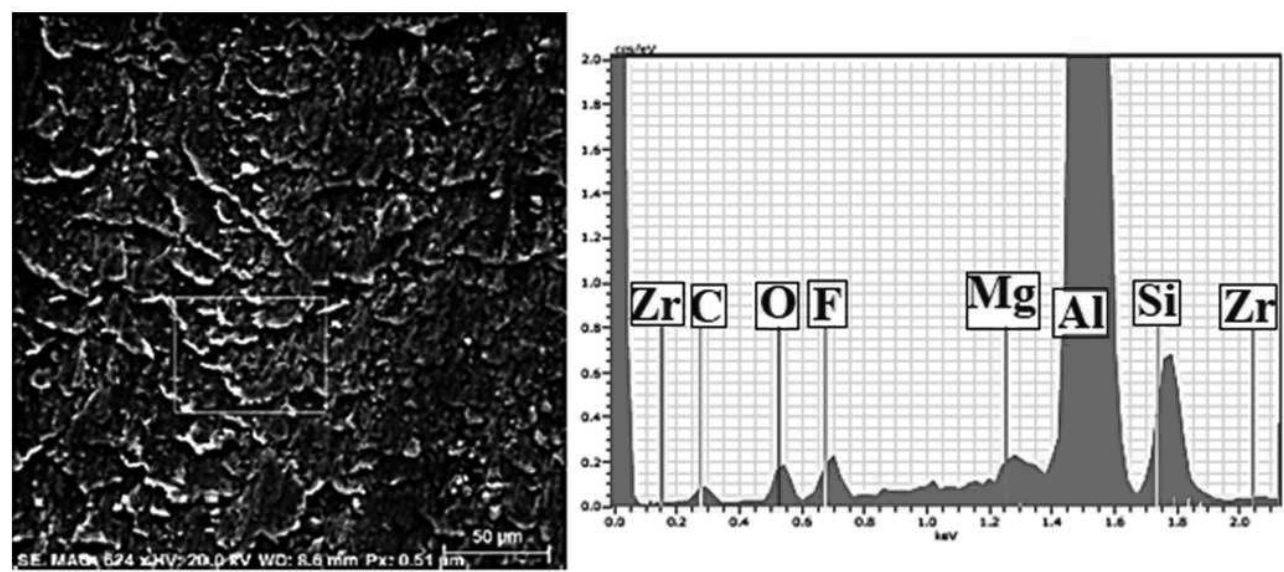

Fig. 12 PTFE coating on the sample surface EDS

\section{Discussion of results}

The findings of the influence of temperature and load duration of the experimental samples on the surface roughness were the first performed analysis. The measurement was carried out on the base material (before coating) and after coating in a way that it would be possible to compare the effect of the coating on the surface roughness. Futhermore, the roughness measurement was performed on both the thermally loaded and not thermally loaded samples. The values of the roughness of the coated material $\left(R a, R_{z}\right.$ i $\left.R \theta\right)$ are lower than the values of the base material. Using the coating helped to level out any surface inequalities of the tested material. The samples with the PTFE coating were put under loading for 30 and 60 minutes. The samples which were put under loading for 30 minutes show lower roughness values. The $2 \mathrm{~B}$ sample group displays the lowest values of the coating roughness, and it was put under loading for 30 minutes. The $2 \mathrm{~B}$ group represents the PTFE coating which was exposed to the temperature of $200{ }^{\circ} \mathrm{C}$. The $7 \mathrm{~B}$ sample group displays the lowest values of the PTFE $+\mathrm{TiO}_{2}$ coating roughness, and it was put under loading for 60 minutes. The $7 \mathrm{~B}$ group represents the PTFE $+\mathrm{TiO}_{2}$ coating which was exposed to the temperature of 500 ${ }^{\circ} \mathrm{C}$. This measurement verified that neither temperature nor time affects the roughness significantly. The roughness values do not display significant discrepancies, and thus it was not possible to draw a clear conclusion.

The measurement of the friction coefficient was performed on a Bruker UMT TriboLab apparatus. The comparison of the friction coefficient of the base material with the coated materials proved that there is an increase of the friction coefficient with the coating (PTFE or PTFE $+\mathrm{TiO}_{2}$ ). The friction coefficient increases sharply when the temperature rises. The PTFE coating degraded at $350^{\circ} \mathrm{C}$ which manifests through a sharp increase of the friction coefficient starting at this temperature. The $1 B 9$ sample shows the lowest average value of the friction coefficient. It is the sample with the PTFE coating which was put under loading at $150{ }^{\circ} \mathrm{C}$ for 60 minutes. The coefficient of friction increases sharply with the rising temperature as it was the case with the PTFE coating. There was a significant increase in the coefficient of friction from the temperature of $300{ }^{\circ} \mathrm{C}$ and up. The $3 A 6$ sample shows the lowest average value of the friction coefficient. It is the sample with the PTFE+ $\mathrm{TiO}_{2}$ coating which was put under loading at $150{ }^{\circ} \mathrm{C}$ for 30 minutes. The friction coefficient increases significantly with the rising temperature with the PTFE coating as well as the $\mathrm{PTFE}+\mathrm{TiO}_{2}$ coating.

\section{Conclusion}

This research aimed to evaluate the thermal stability of the PTFE coating with the addition of nanoparticles on the base material made from Al-Si alloy. For the experiment purposes, there were samples with the PTFE and PTFE $+\mathrm{TiO}_{2}$ coating. Each coating was put under loading for 30 and 60 minutes with set temperatures in the range between 150 and $500{ }^{\circ} \mathrm{C}$. It is possible to draw the following conclusions based on the performed measurements. When measuring the surface roughness, the aim was to measure the surface roughness of the experimental samples and evaluate the effect of the thermal loading and the loading duration of the samples with the PTFE coating and PTFE coating with the addition of $\mathrm{TiO}_{2}$. The values of the $\mathrm{R} a, \mathrm{R} z$ and $\mathrm{R} t$ parameters were used for the analysis. It can be stated that the temperature and time do not affect the surface roughness significantly. When comparing the friction coefficient of the base material with the coated materials, it is apparent that with the rising temperature the friction coefficient increases. The sample $1 B 9$ shows the lowest average value of the friction coefficient. It is the sample with the PTFE coating which was put under loading at 150 ${ }^{\circ} \mathrm{C}$ for 60 minutes. The coefficient of friction increases 